\title{
Psychiatric morbidity in newly diagnosed carcinoma cervix and its comparison with benign condition
}

\author{
Rajnish Raj ${ }^{1}$, Nisha Bhagat ${ }^{2 *}$
}

\begin{abstract}
${ }^{1}$ Department of Psychiatry, ${ }^{2}$ Department of Obstetrics and Gynecology, Government Medical College, Patiala, Punjab,
\end{abstract} India

Received: 22 August 2017

Accepted: 16 September 2017

*Correspondence:

Dr. Nisha Bhagat,

E-mail: nishabhagat07@yahoo.com

Copyright: (c) the author(s), publisher and licensee Medip Academy. This is an open-access article distributed under the terms of the Creative Commons Attribution Non-Commercial License, which permits unrestricted non-commercial use, distribution, and reproduction in any medium, provided the original work is properly cited.

\section{ABSTRACT}

Background: To study the psychiatric morbidity among newly diagnosed carcinoma cervix and its comparison with benign gynaecological diseases of cervix. Cervical cancer is the second most common cancer in the world and ranked first in India. It is mainly caused by sexually transmitted infection (STI) of human papilloma virus (HPV).

Methods: It was an open labeled, cross-sectional and extended phase study that screened 158 patients in the age group of 18-70 years who fulfilled both inclusion and exclusion criteria and screened positive on liquid based cytology (LBC), as per guidelines of Bathesda system in Government Medical College, Patiala. 13 patients dropped out of study and finally 145 patients were enrolled. They were further divided after biopsy into two groups as per histopathological examination (HPE) i.e., Group-1, N=47 women HPE positive for cervical intraepithelial neoplasia (CIN) as Cases and Group-2, N=98 HPE negative as Control Hospital Anxiety Depression Scale (HADS) was used to screen psychiatric morbidity for depression and anxiety. Whereas, severity was assessed on Hamilton Rating Scale for Depression (HAM-D) and Hamilton Rating Scale for Anxiety (HAM-A).

Results: Mean age of Group-1 was 38.45 \pm 11.22 SD years and Group-2 was $36.67 \pm 8.54$ SD years. Psychiatric morbidity in Group-1 was $65.95 \%$ whereas Group- 2 was $21.42 \%$. P value obtained on comparing HADS score of two groups was significant $(\mathrm{p}<0.050)$. After active intervention there was a significant reduction in psychiatric morbidity of two groups (72\% in Group-1 and $81.3 \%$ in Group-2).

Conclusions: The study revealed that the breaking of bad news has a significant psycho-social impact on patients suffering from carcinoma cervix than benign group.

Keywords: Hospital anxiety depression scale (HADS), Cervical intraepithelial neoplasia (CIN), Hospital Hamilton rating scale for depression (HAM-D), Hamilton rating scale for anxiety (HAM-A), International classification of diseases (ICD-10)

\section{INTRODUCTION}

Cervical cancer is the second most common cancer in the world and ranked first in India. ${ }^{1}$ It is mainly caused by sexually transmitted infection (STI) of human papilloma virus (HPV). The patients of cervical cancer are associated with negative labels by general public because of their promiscuous behavior and unwillingness to have protected sex. They themselves have expressed shame, self-blame, guilt and fear of social exclusion. ${ }^{2}$ The introduction of cancer cervix screening programme for selected population induces fear and anxiety, which may be detrimental for mental health. ${ }^{3}$ The diagnoses and treatment of cancer have significant impact on physical, psychological, emotional and social aspects of individual and culture. The most common psychiatric disorder observed in cancer patients is adjustment disorder with depression, anxiety or both. Anxiety is an unpleasant 
affective state that stems from fear of death, apprehension about treatment, and a dread of possible infertility resulting from surgical or chemotherapeutic treatment. It also arises from fear of abandonment, social isolation and anticipatory loss. Depression could be attributed to perceived loss of femininity or separation from one's own family. 4

Scientists believed that epigenetic factors play a vital role in etiology of clinical depression and manifestation of other mental illnesses with/without cultural variations. Genes hold the instructions; epigenetic directs how these instructions are to be carried out. The allele (genetic variant) in the serotonin system, produces symptoms of depression in combination with environmental conditions e.g., maladjustment or maternal deprivation during critical period. After birth such person lacks gene that encodes for specific protein, which acts on hippocampus of the brain and thus, results in deficient coping strategies to deal with stress. ${ }^{5}$

Normal stress is useful which prepares the organism to survive by activating either fight or flight response for self-preservation. Daniel Kahneman (thinking fast versus thinking slow) gave dual process theory of brain function i.e., intuitive (System-1) and deliberate (System-2) responses. It involved activation of amygdale or limbic system in System-1 and prefrontal cortex for System-2 during cognitively appraisal task of physiologically arousing stimuli. ${ }^{6}$ Psychopathology occurs when homeostasis between cognitive-affective-environmental network get disrupted, creating unstable and unpredictable conditions e.g., depression, fear, anxiety, panic etc.

In vulnerable group of patients, the general outcome is depression or anxiety shortly after diagnosis that possibly diminishes during and after therapy. ${ }^{7}$ When the treatment of cancer patients was successful and perceived prognosis is good, the symptoms of anxiety and depression can reach the level of general population. ${ }^{8}$

Hospital Anxiety Depression Scale (HADS) is used in patients with exclusion of symptoms caused by somatic illness. ${ }^{9}$ It has been recommended for use in oncology patients. ${ }^{10}$ The psychometric properties of HADS have been tested in HUNT study and they are considered to be excellent. ${ }^{11}$

Walker et al, found that total HADS score with cut off 15 has an excellent sensitivity of 0.87 , specificity of 0.85 and positive predictive value of 0.35 for major depressive disorder. ${ }^{12}$ The reliability, validity and factor structure of the HADS has been established in a variety of clinical populations of cancer patients. ${ }^{13}$

The present study is an attempt to find the role of acute stress and manifestation of psychiatric morbidity in newly diagnosed carcinoma cervix patients and compare with benign cervical conditions with following aims and objectives:

- To assess the frequency and nature of psychiatric morbidity among women attending the gynecological oncology outpatient clinic.

- To compare the frequency and nature of psychiatric morbidity among gynecological outpatients with normal/benign cervical diseases.

- To study the relationship between sociodemographic variables and the psychiatric morbidity.

- To compare the progression or degression of psychiatric morbidity before and after appropriate treatment intervention in both groups.

\section{METHODS}

An observational, cross-sectional and extended phase study was conducted in Department of Psychiatry and Department of Gynecology of Government Medical College, Patiala. Study lasted for 6 months from June 2014 to December 2014. A total of 158 patients, in the age group of 18-70 years were screened, who reported to Out Patient Department (OPD) of Gynecological oncology for bleeding per vaginum, post-coital bleeding, post-menopausal bleeding, intermenstrual or abnormal bleeding per vaginum and were screened positive on Liquid Based Cytology (LBC) as per Bathesda system. ${ }^{14}$ Eight patients withdrew their consent and five patients were lost to follow-up. Finally, 145 patients were enrolled for the study that fulfilled both inclusion and exclusion criteria. Patients' demographic variables such as age, locality, marital status, education and socioeconomic status were recorded. All patients gave their written informed consent and study had an approval of College Ethical Committee clearance as per the declaration of Helsinki's that adhered to Good Clinical Practice guidelines.

\section{Inclusion criteria}

Women aged more than 18 years with complaints of discharge per vaginum, post-coital bleeding, irregular bleeding per vaginum, post-menopausal bleeding, chronic backache, naked eye abnormality of suspicious cervix and patients with high risk factors e.g., early age of marriage, high parity and multiple partners and who turned out to be screen positive on LBC.

\section{Exclusion criteria}

Patients with gross cognitive deficits, too sick or distressed to participate, prior history of psychiatric illness, with major medical problems like severe hypertension, uncontrolled diabetes, intra-cranial space occupying lesions and substance use disorder were excluded from the study.

Cervical biopsies were done in all 145 patients for final confirmation of diagnosis and then divided in two groups. 
Group-1 (Cases, N=47) were histopathological examination (HPE) confirmed CIN positive cases whereas Group-2 (Control, N=98) patients were normal or with benign findings on HPE (chronic cervicitis). These patients were screened for psychiatric morbidity using HADS (Hospital Anxiety Depression Scale), which consist of seven items on anxiety (HADS-A) and seven items on depression (HADS-D) subscale. ${ }^{15}$

The cut-off value for the screening as clinical case was set at HADS score of 11. It delineates the psychiatric workload prior to ascertaining the role of breaking bad news as a risk factor for acute onset (2-3 days) stress amongst vulnerable population that may have the potential to confound results of the study hence, controlled to rule out bias.

At 2 weeks, after breaking the bad news of cancer cervix; patients were assessed for the impact of acute stress amongst both groups. They were assessed and reviewed by an experienced psychiatrist (R.R.) for psychopathology on International Classification of Diseases (ICD-10) and degree of severity on Hamilton Anxiety Rating Scale, 1959 (HAM-A) that comprises of fourteen items, clinician-rated to evaluate severity of anxiety. ${ }^{16}$ It takes 10 minutes; each item is scored on a five-point scale and yields a comprehensive score in the range of 0 to 56 . A score of 17 or less indicates mild, 18 to 24 indicates moderate and 25 to 30 indicates severe anxiety. Sensitivity is $85.7 \%$ and specificity is $63.5 \% .^{17}$

Hamilton Rating Scale for Depression, HAM-D is a multiple item questionnaire used to provide an indication of depression, and as a guide to evaluate recovery. Originally published in 1960 and contains 17 items to be rated. Each item on the questionnaire is scored on a 3 or 5 point scale. Assessment time is estimated at 20 minutes. Eight items are scored on a 5-point scale, ranging from 0 $=$ not present to $4=$ severe. Nine are scored from $0-2$. The sensitivity is $86.4 \%$ and specificity is $92.2 \% .^{18}$

The appropriate gynaecological treatment, psychiatric treatment and counseling were given. The subjects having psychiatric morbidity amongst both the groups were managed by giving escitalopram in the dose of 5-20 mg with/without benzodiazepine as per the severity of anxiety and depression. After initiation of treatment, the follow-up assessment was done on HAM-D and HAM-A scales at $2^{\text {nd }}$ week (baseline) and $12^{\text {th }}$ weeks and Clinical Global impression (CGI) score was compared for the change in improvement, within or between the groups. ${ }^{19}$

\section{Statistical analysis}

Data thus obtained was spread in Microsoft excel sheet and then transferred to Statistical Package for Social Sciences, version 16.0 (SPSS) software.
The results were shown as mean \pm Standard deviation (SD). Independent t-test was used to analyze quantitative variables between the two groups i.e., Group-1 and Group-2. Chi-square test was used to check for the association between psychiatric morbidity and sociodemographic factors. Depression and anxiety were diagnosed on ICD-10 and severity on HAM-D and HAMA. For dependent variables amongst groups, t-test was used to compare HAM-D and HAM-A scores before and after treatment intervention. $\mathrm{P}$ value of less than 0.05 was considered statistically significant.

\section{RESULTS}

A total of 145 patients were screened. Most of the patients $(35.86 \%)$ in our study group were in the age group of more than 45 years and were married $(58.62 \%)$. More subjects $(53.79 \%)$ were found to have low educational status and studied up to high school. Most of the subjects in studied sample population belonged to lower socio-economic strata $(70.2 \%)$ and $51.72 \%$ were from the urban area. $32.41 \%(n=47)$ and $67.58 \%(n=98)$ belonged to Group-1 (Cases) and Group-2 (Control), respectively. The Gynecological diagnoses in both the groups is depicted in pie chart (Figure 1).

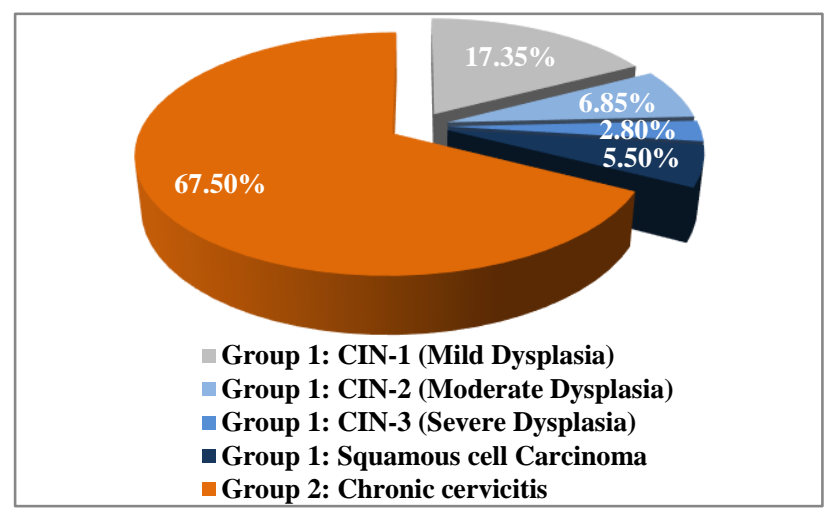

Figure 1: Gynecological diagnoses in both the groups.

The mean age of Group-1 was $38.45 \pm 11.22$ years and that of Group-2 was $36.67 \pm 8.54$ years. The sociodemographic profile and its relationship with psychiatric morbidity is shown in Table 1 .

In Group-1 higher rates of psychiatric morbidity was found on HADS in those who were illiterate than literate $(64.51 \%$ versus $35.48 \%)$ with level of significance at $\mathrm{p}<0.03$; on comparing the marital status, widow/single women had higher psychiatric morbidity than married subjects $(67.74 \%$ versus $32.25 \%)$ with significant at $\mathrm{p}$ value of $<0.021$; amongst socio-economic status i.e., lower to middle-upper strata $(61.29 \%$ versus $38.70 \%)$ showed highly significant $\mathrm{p}<0.002$. There was no association between age, locality with psychological maladjustment at $p$ value of $>0.05$ non-significant. 
Table 1: Socio- demographic profile and psychiatric morbidity within groups.

\begin{tabular}{|c|c|c|c|c|c|c|c|c|c|c|c|c|}
\hline & \multicolumn{6}{|c|}{$\begin{array}{l}\text { Cases (Group-1) N=47 } \\
\text { Psychiatric morbidity (HADS) }\end{array}$} & \multicolumn{6}{|c|}{$\begin{array}{l}\text { Control (Group-2) N=98 } \\
\text { Psychiatric morbidity (HADS) }\end{array}$} \\
\hline & Yes & No & Total & Chi square & $P$ value & df & Yes & No & Total & Chi square & $P$ value & df \\
\hline \multicolumn{13}{|l|}{ Age } \\
\hline 30 yrs & 7 & 5 & 12 & 1.276 & 0.528 & 2 & 7 & 26 & 33 & 0.292 & 0.864 & 2 \\
\hline $31-35$ & 9 & 6 & 15 & & NS & & 8 & 25 & 33 & & NS & \\
\hline$>45 y r s$ & 15 & 5 & 20 & & & & 6 & 26 & 32 & & & \\
\hline Total & 31 & 16 & 47 & & & & 21 & 77 & 98 & & & \\
\hline \multicolumn{13}{|l|}{ Locality } \\
\hline Urban & 13 & 8 & 21 & 0.278 & 0.598 & 1 & 13 & 41 & 54 & 0.5 & 0.48 & 1 \\
\hline Rural & 18 & 8 & 26 & & NS & & 8 & 36 & 44 & & NS & \\
\hline Total & 31 & 16 & 47 & & & & 21 & 77 & 98 & & & \\
\hline \multicolumn{13}{|l|}{ Education } \\
\hline Illiterate & 20 & 5 & 25 & 4.691 & $0.03 *$ & 1 & 11 & 42 & 53 & 0.318 & 0.573 & 1 \\
\hline Literate & 11 & 11 & 22 & & $\mathrm{~S}$ & & 10 & 35 & 45 & & NS & \\
\hline Total & 31 & 16 & 47 & & & & 21 & 77 & 98 & & & \\
\hline \multicolumn{13}{|c|}{ Socio-economic status } \\
\hline Upper & 3 & 9 & 12 & 12.242 & $0.002 * *$ & 2 & 6 & 36 & 29 & 2.25 & 0.325 & 2 \\
\hline Middle & 9 & 3 & 12 & & HS & & 7 & 20 & 27 & & NS & \\
\hline Lower & 19 & 4 & 23 & & & & 8 & 21 & 42 & & & \\
\hline Total & 31 & 16 & 47 & & & & 21 & 77 & 98 & & & \\
\hline \multicolumn{13}{|c|}{ Marital status } \\
\hline Married & 10 & 14 & 24 & 5.328 & $0.021^{*}$ & 1 & 10 & 51 & 61 & 2.618 & 0.106 & 1 \\
\hline Single/widow & 21 & 2 & 23 & & $\mathrm{~S}$ & & 11 & 26 & 37 & & NS & \\
\hline Total & 31 & 16 & 47 & & & & 21 & 77 & 98 & & & \\
\hline
\end{tabular}

Table 2: Socio-demographic profile and psychiatric morbidity between groups.

\begin{tabular}{|c|c|c|c|c|c|}
\hline & $\begin{array}{l}\text { Group- } \\
1(\%)\end{array}$ & $\begin{array}{l}\text { Group- } \\
2(\%)\end{array}$ & $\begin{array}{l}\text { Chi } \\
\text { square }\end{array}$ & $\begin{array}{l}P \\
\text { value }\end{array}$ & df \\
\hline \multicolumn{6}{|l|}{ Age } \\
\hline 30 yrs & $15 \%$ & $7 \%$ & 2.600 & 0.273 & 2 \\
\hline $31-35$ yrs & $19 \%$ & $8 \%$ & & NS & \\
\hline$>45 \mathrm{yrs}$ & $32 \%$ & $6 \%$ & & & \\
\hline \multicolumn{6}{|l|}{ Locality } \\
\hline Urban & $28 \%$ & $13 \%$ & 2.426 & 0.119 & 1 \\
\hline Rural & $38 \%$ & $8 \%$ & & NS & \\
\hline \multicolumn{6}{|l|}{ Education } \\
\hline Illiterate & $43 \%$ & $11 \%$ & 1.104 & 0.293 & 1 \\
\hline Literate & $23 \%$ & $10 \%$ & & NS & \\
\hline \multicolumn{6}{|c|}{ Socio-economic } \\
\hline Upper & $6 \%$ & $6 \%$ & 6.127 & 0.047 & 2 \\
\hline Middle & $19 \%$ & $7 \%$ & & $S$ & \\
\hline Lower & $41 \%$ & $8 \%$ & & & \\
\hline \multicolumn{6}{|l|}{ Marital status } \\
\hline Married & $15 \%$ & $7 \%$ & 0.949 & 0.33 & 1 \\
\hline Single/widow & $51 \%$ & $14 \%$ & & NS & \\
\hline
\end{tabular}

In Group-2, there was no association of sociodemographic variable with psychiatric morbidity ( $\mathrm{p}$ value $>0.05$ ). On comparing results of cases with control, $p$ $>0.1$ was obtained which revealed that two groups were comparable on most of the psychosocial variables except for socio-economic status with significant $p$ value of 0.047 in Table 2.

\section{Psychiatric morbidity}

Total of fifty two $(35.86 \%)$ women who participated in the study, at least one of the diagnoses was depression $(\mathrm{n}=27,18.62 \%)$ and anxiety $(\mathrm{n}=25,17.24 \%)$.

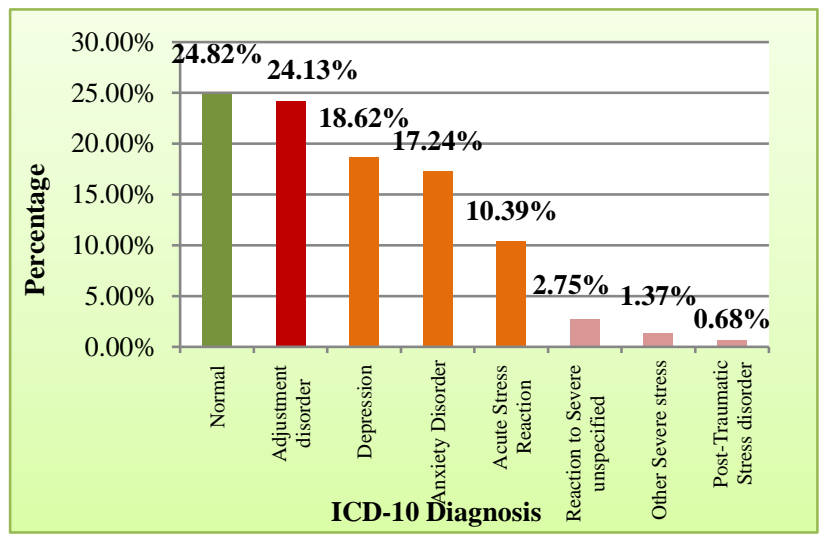

Figure 2: Overall ICD-10 diagnosis.

In rest of the study group, overall percentage of reaction to severe stress, and adjustment disorders were $n=57$, 
$(39.31 \%)$. It comprised of acute stress reaction $(n=15$, $10.34 \%)$, post-traumatic stress disorder PTSD $(n=1$, $0.68 \%)$, adjustment disorder $(n=35,24.13 \%)$, other reaction to severe stress $(\mathrm{n}=2,1.37 \%)$ and reaction to severe stress, unspecified $(\mathrm{n}=4,2.75 \%)$ whereas 36 $(24.82 \%)$ patients were normal (Figure 2 ).

Table 3: Severity of psychiatric morbidity.

\begin{tabular}{|c|c|c|c|c|c|}
\hline & \multicolumn{2}{|c|}{$\begin{array}{l}\text { Cases } \\
\text { (Group-1) } \\
\mathbf{N}=\mathbf{3 1 / 4 7}\end{array}$} & $\begin{array}{l}\text { Control } \\
\text { (Group-2) } \\
N=21 / 98\end{array}$ & \multicolumn{2}{|c|}{$\begin{array}{l}\text { Total } \\
N=52 / 145\end{array}$} \\
\hline \multicolumn{6}{|l|}{ HAM-D } \\
\hline Mild & 3 & & 5 & 8 & \\
\hline Moderate & 10 & 19 & 8 & 12 & 27 \\
\hline Severe & 6 & & 1 & 7 & \\
\hline \multicolumn{6}{|l|}{ HАМ-А } \\
\hline Mild & 4 & & 10 & 14 & \\
\hline Moderate & 6 & 12 & 13 & 8 & 25 \\
\hline Severe & 2 & & 1 & 3 & \\
\hline Total & & 31 & 21 & & 52 \\
\hline
\end{tabular}

Hamilton Rating Scale for Depression HAM-D: Normal $(<9)$, mild (10-13), moderate (14-17) and severe (>17); Hamilton Rating Scale for Anxiety HAM-A: Normal $(<11)$, mild $(12-17)$, moderate $(18$ 24) and severe (25-30)
Thirty one subjects out of 47 cases in Group-1 had some sort of mental maladjustment either anxiety or depression, accounting to $65.95 \%$ of psychiatric morbidity whereas in Group-2 overall psychiatric illnesses was $21.42 \%$ (21 patients out of 98 ).

Degree of severity for depression and anxiety on HAM-D and HAM-A scales, as done at 2 weeks after breaking the bad news, among Group-1 and Group-2 are shown in Table 3 .

Mean value of HAM-D in Group-1 was $16.21 \pm 2.55$ and in Group-2 was 12.12 \pm 2.79 . Average score of HAM-A in Group-1 was 20.16 \pm 4.32 and in Group-2 was $15.75 \pm 3.65$.

On comparing the results of HAM-D score in two groups, statistically highly significant $\mathrm{p}$ value of $<0.001 * *$ was obtained while on comparison of HAM-A score, $\mathrm{p}$ value of $<0.011^{*}$ was seen which was statistically significant. It showed that both depression and anxiety was of moderate in degree of severity (Table 4).

Table 4: Comparison of HAM scoring between Group-1 and Group-2.

\begin{tabular}{|c|c|c|c|c|c|c|c|c|c|}
\hline & & & & & & C.I. & & Overa & \\
\hline & Groups & Mean & S.D. & $p$ value & Significance & Lower & Upper & Mean & S.D. \\
\hline \multirow[t]{2}{*}{ HAM-D } & Cases & 16.21 & \pm 2.55 & $0.001 * *$ & HS & 1.809 & 6.363 & 15.00 & \pm 3.199 \\
\hline & Controls & 12.12 & \pm 2.79 & & & & & & \\
\hline \multirow[t]{2}{*}{ HAM-A } & Cases & 20.16 & \pm 4.32 & $0.011^{*}$ & S & 1.094 & 7.701 & 17.88 & \pm 4.503 \\
\hline & Controls & 15.76 & \pm 3.65 & & & & & & \\
\hline
\end{tabular}

Level of significance at $\mathrm{p}<0.001 * * \mathrm{HS}$, highly significant; Level of significance at $\mathrm{p}<0.011^{*} \mathrm{~S}$, significant; C.I. confidence interval; S.D. \pm standard deviation

Table 5: Scores of HAM-D and HAM-A at baseline (2 weeks) and after treatment intervention (12 weeks).

\begin{tabular}{|c|c|c|c|c|c|c|c|c|c|c|c|}
\hline \multirow{2}{*}{ HAM-D } & \multirow{2}{*}{ Mean } & \multirow{2}{*}{ S.D. } & \multirow{2}{*}{$p$ value } & \multicolumn{2}{|l|}{ C.I. } & \multirow{2}{*}{ HAM-A } & \multirow{2}{*}{ Mean } & \multirow{2}{*}{ S.D. } & \multirow{2}{*}{ p value } & \multicolumn{2}{|l|}{ C.I. } \\
\hline & & & & Lower & Upper & & & & & Lower & Upper \\
\hline \multicolumn{6}{|c|}{ Group-1 (Cases) } & \multicolumn{6}{|c|}{ Group-1 (cases) } \\
\hline 2 weeks & 16.21 & 2.55 & $<0.001 * *$ & 4.687 & 5.839 & 2 weeks & 20.16 & 4.32 & $<0.001 * *$ & 5.872 & 8.461 \\
\hline 12 weeks & 10.94 & 1.89 & & & & 12 weeks & 13.00 & 2.82 & & & \\
\hline \multicolumn{6}{|c|}{ Group-2 (Control) } & \multicolumn{6}{|c|}{ Group-2 (control) } \\
\hline 2 weeks & 12.12 & 2.79 & $<0.001 * *$ & 1.741 & 4.009 & 2 weeks & 15.76 & 3.65 & $<0.001 * *$ & 3.124 & 6.107 \\
\hline 12 weeks & 9.25 & 1.75 & & & & 12 weeks & 11.15 & 1.34 & & & \\
\hline \multicolumn{6}{|c|}{ Entire study group } & \multicolumn{6}{|c|}{ Entire study group } \\
\hline 2 weeks & 15.00 & 3.19 & $<0.001 * *$ & 3.903 & 5.208 & 2 weeks & 17.88 & 4.50 & $<0.001 * *$ & 4.776 & 6.904 \\
\hline 12 weeks & 10.44 & 1.98 & & & & 12 weeks & 12.04 & 2.33 & & & \\
\hline
\end{tabular}

Level of significance at $\mathrm{p}<0.001 * * \mathrm{HS}$, highly significant

After the initial evaluation of illness, appropriate gynaecological and psychiatric treatment was given. While all subjects in Group-2 were kept for routine screening by LBC, active surgical intervention was done in Group-1. Electro-cautery excision was done in 10 patients, trachelectomy in four and hysterectomy in eight subjects. 25 patients diagnosed as CIN-1 were kept for regular screening by $\mathrm{LBC}$ every six months.

Psychiatric illness was assessed at 2nd week. Depressed and anxious patients were given treatment at 2 weeks (baseline) with antidepressant and on follow-up at 12th 
week with HAM-A and HAM-D scale. Comparison of HAM-D and HAM-A scores of two groups showed significant $\mathrm{p}$ value of $<0.001$ (Table 5). In Group-1, there was $72 \%$ of reduction in severity of psychiatric illness as compared to $81.3 \%$ in Group-2. The higher degree of response can be attributed to higher percentage of mild to moderate degree of severity in both the groups that might have responded to an early treatment intervention with antidepressants.

Table 6: Post-Hoc analysis of clinical global impression (CGI).

\begin{tabular}{|c|c|c|c|c|c|c|c|c|c|c|c|c|c|}
\hline \multicolumn{12}{|c|}{ C.I. } & \multicolumn{2}{|l|}{ C.I. } \\
\hline Depression & Mean & S.D & $\begin{array}{l}\mathbf{p} \\
\text { value }\end{array}$ & Signi. & Lower & Upper & Anxiety & Mean & S.D & $\begin{array}{l}\mathbf{p} \\
\text { value }\end{array}$ & Signi. & Lower & Upper \\
\hline Cases & & & & & & & Cases & & & & & & \\
\hline Pre CGI-S & 4.474 & 1.124 & 0.001 & HS & 1.302 & 1.961 & $\begin{array}{l}\text { Pre } \\
\text { CGI-S }\end{array}$ & 4.818 & 0.751 & $<0.001$ & HS & 2.025 & 2.703 \\
\hline Post CGI-I & 2.842 & 1.119 & & & & & $\begin{array}{l}\text { Post } \\
\text { CGI-I }\end{array}$ & 2.455 & 0.820 & & & & \\
\hline Control & & & & & & & Control & & & & & & \\
\hline Pre CGI-S & 1.5 & 1.195 & 0.007 & HS & 0.368 & 1.632 & $\begin{array}{l}\text { Pre } \\
\text { CGI-S }\end{array}$ & 3.692 & 1.182 & $<0.001$ & HS & 1.755 & 2.091 \\
\hline Post CGI-I & 0.5 & 0.535 & & & & & $\begin{array}{l}\text { Post } \\
\text { CGI-I }\end{array}$ & 1.769 & 1.166 & & & & \\
\hline
\end{tabular}

Clinical Global Impression-Severity (CGI-S); Clinical Global Impression-Improvement (CGI-I); Level of significance at p <0.001 HS, highly significant

There was significant improvement in CGI scoring in patients with depression and anxiety in both groups. $\mathrm{P}$ value while comparing results of severity of depressive and anxiety at 2 weeks (pre CGI-S) and 12 weeks (post CGI-I) in Group-1 was 0.001 and $<0.001$ respectively, which was highly significant. Similarly, on comparison in Group-2, patients of depression and anxiety revealed a $\mathrm{p}$ value of 0.007 and $<0.001$ respectively (Table 6).

\section{DISCUSSION}

Stress is conceptualized as pressure, force or demand placed on the organism. It allows a person to respond either by adapting or adjusting to these life demands. Hans Selye described biological response pattern as general adaptation syndrome (GAS) to stress. ${ }^{20}$ Walter Cannon renamed this response pattern as flight-or-fight response. GAS model consists of three processes. The alarm reaction, resistance stage and exhaustion phase. There are three models to understand theories of stress: response-based, transactional (cognitive-appraisal) and stimulus-based. They focus on specific relationship between bodily process, psychological components and external demands. ${ }^{21,22}$

Cervical cancer is usually preceded by CIN. The earlier detection of cervical screen and effective treatment has improved the survival rates. Despite improved survival rates, treatment of cervical cancer often results in significant morbidity. The diagnosis of cervical cancer has physical, psychosexual, psychosocial implications and financial burden both on individuals and on society as a whole. ${ }^{23}$
James- Lange, Cannon-Bard and Schachter-Singer hypothesized that emotions such as stress or fear responses and anxiety are evolutionary/adaptive reaction to threatening situations. ${ }^{24-26}$ Pathological reactions to severe stress can cause mental or/and physical illness. Event or life experiences might be unexpected and requires unique demands on person's adaptive abilities and adjustment to physical, psychological, intellectual and social parameters. ${ }^{27}$

There is dearth of paucity of research in cancer and mental health. Studies have elucidated the role of depression in cancer patients having a negative impact on morbidity and mortality and depression being an independent predictor of poor survival in advanced stage of cancer. ${ }^{28}$ The co-existence of cancer and depression is associated with a significantly increased risk of death, although the effect of depression differs by cancer site. ${ }^{29}$

A significant number of papers looked at the effect of cancer diagnosis and treatment on patients and their families. ${ }^{30}$ Several studies have attempted to examine prevalence of psychiatric morbidity in heterogeneous samples of cancer patients in India. ${ }^{31,32}$ The reported prevalence of diagnosable psychiatric conditions in these studies tends to range between $40 \%$ and $80 \%$. A study conducted by Mendonsa et al., revealed $50 \%$ of psychiatric morbidity in cancer group as compared to $42 \%$ of benign group while Lau et al., showed prevalence of $31 \%$ depressive disorders and anxiety disorders of $16 \% .33,34$

In present study, $65.95 \%$ of psychiatric illness was noted in cases as compared to control group of $21.42 \%$. 
Depression comprised of $18.62 \%$ and anxiety $17.24 \%$ amongst the entire study group. The percentage of morbidity in controls may be attributed to fear of contracting disease in future as these subjects were CIN positive during the initial screen by LBC. The depression in women of gynecological cancer tends to be moderate in severity as compared to women with benign gynecological conditions who were likely to have mild depressive symptoms. No study till date has shown the effect of various interventional methods on psychiatric morbidity. The study revealed $72 \%$ and $81.3 \%$ reduction in psychiatric morbidity of cancer and benign group. These combined gynaecological, psychological and pharmacological-therapeutic approach was statistically significant when compared to pre-intervention morbidity $(\mathrm{p}<0.01)$.

\section{Limitations}

Although subjects with previous psychiatric morbidity were excluded from the study yet they may have preponderance to psychiatric illness due to genetic vulnerability. The significant reduction in psychiatric morbidity after treatment cannot specifically be attributed to psycho-pharmacological intervention. There is possibility of contributory bias from individual's psychic abilities to cope and overcome stress or active gynecological intervention, thus these results should be interpreted cautiously and requires large sample size for generalization.

\section{CONCLUSION}

The study concluded that the breaking of bad news of carcinoma cervix has a significant psychological impact on patients as evident by $65.95 \%$ of psychiatric morbidity in Group-1 compared to $21.42 \%$ of Group-2. Interdisciplinary approaches in management of these patients result in improvement of psychological stress. Thus, it is recommended to incorporate non-judgmental and professional approach for the well being of such patients. Stress disrupts information processing, belief retrieval and one's ability to respond to noxious environmental stimuli. These external events result in functional change of brain's plasticity and lend support to the classic nature-versus-nurture paradigm. This article is intended for interdisciplinary approach in expanding knowledge vis-à-vis of epigenetic risk and formulating optimal management program.

Many studies have discussed the prevalence of psychiatric morbidity in carcinoma patients but very few studies have determined outcome measures after active intervention. Our study reported higher percentage of psychiatric maladjustment in carcinoma cervix patients prior to the start of treatment. However, after active intervention there was significant improvement. It strengthens the role of interdisciplinary management approach in patient care.

\section{Recommendations}

The futuristic research work of Brain-mind-interface is in developing stage. It incorporates discovery and insertion of specific genes that target light sensitive opsin cells and confer responsiveness, control and modulation of person's behavior on real time basis and thus, emphasizes the role of Optogenetics in ameliorating stress.

Funding: No funding sources

Conflict of interest: None declared

Ethical approval: The study was approved by the Institutional Ethics Committee

\section{REFERENCES}

1. Kaarthigeyam K. Cervical cancer in India and HPV vaccination. Indian $\mathrm{J}$ Med Pediatric Oncol. 2012;33:7-12.

2. Yang YL, Liu L, Wang Y, Wu H, Yang XS, Wang JN, Wang L. The prevalence of depression and anxiety among Chinese adults with cancer: a systematic review and meta-analysis. BMC Cancer. 2013;13:393.

3. Marteau TM. The psychological costs of screening. BMJ. 1989;299:527.

4. Derogatis RL, Wise TM. Anxiety and Depressive Disorders in Medical Patients. Washington: American Psychiatric Press; 1989.

5. Weaver IC, Cervoni N, Champagne FA, D'Alessio AC, Sharma S, Seckl JR et al. Epigenetic programming by maternal behavior. Nat Neurosci. 2004; 7(8): 847-54.

6. Kahneman D. Thinking fast and slow. New York: Farrar, Straus \& Giroux; 2011.

7. Iconomou G, Mega V, Koutras A, Iconomou AV, Kalofonos HP. Prospective assessment of emotional distress, cognitive function, and quality of life in patients with cancer treated with chemotherapy. Cancer. 2004;101:404-11.

8. De Bock GH, Bonnema J, Zwaan RE, Van De Velde CJH, Kievit J, Stiggelbout AM. Patient's needs and preferences in routine follow-up after treatment for breast cancer. Br J Cancer. 2004;90:1144-50.

9. Zigmond AS, Snaith RP. The Hospital Anxiety and Depression scale. Acta Psychiatr Scand. 1983;67:361-70.

10. Sharpe M, Strong V, Allen K, Rush R, Postma K, Tulloh A et al. Major depression in outpatients attending a regional cancer centre: Screening and unmet treatment needs. Br J Cancer. 2004;90:314-20.

11. Mykletun A, Stordal E, Dahl AA. The Hospital Anxiety and Depression Scale (HADS): Factor structure, item analyses, and internal consistency in a large population. Br J Psychiatry. 2001;179:540-4.

12. Walker J, Postma K, McHugh GS, Rush R, Coyle B, Strong V et al. Performance of the Hospital Anxiety and Depression Scale (HADS) as a screening tool for major depressive disorder in cancer patients. J Psychosom Res. 2007;63:83-9. 
13. Moorey S, Greer S, Watson M, Gorman C, Rowden $\mathrm{L}$, Tunmore $\mathrm{R}$ et al. The factor structure and factor stability of the hospital anxiety and depression scale in patients with cancer. $\mathrm{Br} \mathrm{J}$ Psychiatry. 1991;158:255-9.

14. Soloman D. The 1988 Bethesda System for reporting cervical/vaginal cytologic diagnoses: developed and approved at the National Cancer Institute workshop in Bethesda, MD, December 12-13, 1988. Diagn Cytopathol. 1989;5(3):331-4.

15. Mykletun A, Stordal E, Dahl A. Hospital Anxiety and Depression (HAD) scale: factor structure, item analyses and internal consistency in a large population. Br J Psychiatry. 2001;179:540-4.

16. World Health Organization. International statistical classification of disease and related health problems (10th edn) ICD-10. Geneva; 1994.

17. Hamilton $\mathrm{M}$. The assessment of anxiety states by rating. Br J Med Psychol. 1959;32:50-55.

18. Hamilton M. A rating scale for depression. J Neurol Neurosurg Psychiatry. 1960;23:56-62.

19. Spearing MK, Post RM, Leverich GS, Brandt D, Nolen W. Modification of clinical Global Impressions (CGI) Scale for use in bipolar illness (BP): the CGI-BP. Psychiatry Res. 1997; 73(3): 15971.

20. Selye H. The stress of life. New York: McGrawHill;1956.

21. Holroyd K, Lazarus R. Stress, coping and somatic adaptation. In: Goldberger L, Breznitz S, editors. Handbook of stress: theoretical and clinical aspects. New York: The Free Press; 1982:21-35.

22. Holmes TH, Rahe RH. The Social Readjustment Rating Scale. J Psychosom Res. 1967;11(2):213-8.

23. Schiffman MH, Brinton LA. The epidemiology of cervical carcinogenesis. Cancer. 1995;76(10 Suppl):1888-901.

24. James W. What is an emotion? Mind. 1884;9:188205.

25. Cannon WB. Bodily changes in pain, hunger, fear and rage. New York: D. Appleton \& Co;1927.
26. Schachter S, Singer J. Cognitive, social and physiological determinants of emotional state. Psychol Rev. 1962;69(5):379-99.

27. Vistad I, Fossa SD, Dahl AA. A critical review of patient-rated quality of life studies of long-term survivors of cervical cancer. Gynecol Oncol. 2006;102:563-72.

28. Lloyd-Williams M, Shiels C, Taylor F, Dennis M. Depression: an independent predictor of early death in patients with advanced cancer. J Affect Disord. 2009; 113(1-2): 127-32.

29. Gathinji M, McGirt MJ, Attenello FJ, Chaichana KL, Than K, Olivi A et al. Association of preoperative depression and survival after resection of malignant brain astrocytoma. Surg Neurol. 2009;71(3):299-303.

30. Hashimoto N, Isaka N, Ishizawa Y, Mitsui T, Sasaki M. Surgical management of colorectal cancer in patients with psychiatric disorders. Surgery. 2009;39(5):393-8.

31. Alexander PJ, Dinesh N, Vidyasagar MS. Psychiatric morbidity among cancer patients and its relationship with awareness of illness and expectations about treatment outcome. Acta Oncologica. 1993;32:623-4.

32. Mishra SK, Mohapatra PK, Bhattacharya K, Gupta T, Agarwal JP. Prevalence of psychiatric disorder in asymptomatic or minimally symptomatic cancer patients on treatment. J Cancer Res Therapeut. 2006;2:136-9.

33. Mendonsa RD, Appaya P. Psychiatric morbidity in outpatients of gynecological oncology clinic in a tertiary care hospital. Indian J Psychiatry. 2010;52(4):327-32.

34. Lau KL, Yim PH, Cheung EY. Psychiatric morbidity in Chinese women after cervical cancer treatment in a regional gynaecology clinic. East Asian Arch Psychiatry. 2013 Dec;23(4):144-53.

Cite this article as: Raj R, Bhagat N. Psychiatric morbidity in newly diagnosed carcinoma cervix and its comparison with benign condition. Int J Reprod Contracept Obstet Gynecol 2017;6:4990-7. 